\title{
Synthesis of alkaline-soluble cellulose methyl carbamate using reactive deep eutectic solvent
}

\author{
Juho Antti Sirviö[a]* Juha P. Heiskanen ${ }^{[b]}$
}

\begin{abstract}
This study presents the use of a reactive deep eutectic solvent (DES) for the chemical modification of wood cellulose fibers. DES based on dimethylurea and $\mathrm{ZnCl} 2$ was used to synthetize cellulose methyl carbamate $(\mathrm{CMeC})$. This synthesis was performed at an elevated temperature under solvent-free conditions. Chemical characterization based on FTIR and NMR indicates that methyl carbamate was successfully introduced to cellulose, and a degree of substitution (DS) of 0.17 was obtained after $3 \mathrm{~h}$ of reaction at $150{ }^{\circ} \mathrm{C}$. The product with a DS of 0.17 exhibited good alkaline-solubility (in $3 \%$ $\mathrm{NaOH}$ solution) after freeze-thawing, whereas the original cellulose fibers were practically insoluble, even in $9 \% \mathrm{NaOH}$. Because dimethylurea can be produced from carbon dioxide, this method can be used as a sustainable way to obtain novel cellulose materials with desirable properties (here alkaline-solubility) for use in a wide range of applications.
\end{abstract}

\section{Introduction}

Cellulose is most abundant biopolymer on earth and is therefore one of the most promising raw materials for sustainable material fabrication. ${ }^{[1]}$ Natural cellulose fibers are widely used in a variety of applications, one of the main utilizations being in paper-making. However, cellulose exhibits several inherent disadvantages as compared to oil-based materials, namely poor formability and solubility. ${ }^{[2]}$ Specifically, the insolubility of cellulose in most common solvents is a major obstacle to the utilization of cellulose in commercial applications.

Several studies have been conducted to improve the solubility of cellulose, and it can be successfully dissolved in dimethylacedamide/LiCl[3], $\quad \mathrm{N}$-methylmorpholine- $\mathrm{N}$-oxide ${ }^{[4]}$, molten salt hydrates ${ }^{[5]}$, and ionic liquids ${ }^{[6]}$, among others. ${ }^{[7]}$ Some solvent systems (organic electrolyte solutions containing ionic liquid) are known to rapidly dissolve cellulose at elevated temperature ${ }^{[8]}$ and few solvent (onium Hydroxides) are also reported to dissolve cellulose even at room temperature. ${ }^{[9]}$ However, many of these solvents exhibit toxic properties and/or are highly expensive. Of the cellulose solvents, $\mathrm{NaOH}$ solution, together with urea ${ }^{[10]}$, thiourea ${ }^{[11]}$, or $\mathrm{ZnO}^{[12]}$, has been proposed as a sustainable alternative. Even though these systems require

\footnotetext{
[a] Dr. J. A. Sirviö

Fibre and Particle Engineering Research Unit

University of Oulu

P.O. Box 4300, FI-90014, Finland

E-mail: juho.sirvio@oulu.fi

[b] Dr. J. P. Heiskanen

Research Unit of Sustainable Chemistry

University of Oulu

P.O. Box 3000, FI-90014, Finland
}

Supporting information for this article is given via a link at the end of the document the energy-intensive cooling of the sample to below $0{ }^{\circ} \mathrm{C}$ (generally around $-12{ }^{\circ} \mathrm{C}$ ), they have been successfully used to obtain cellulose-based materials, such as all-cellulose composites $^{[13]}$ and chemically modified cellulose ${ }^{[14]}$.

Even though $\mathrm{NaOH}$-based cellulose solvent systems are widely used, they have limited solvation capacity with regard to highmolecular-weight cellulose, such as wood fibers. ${ }^{[15,16]}$ The dissolution of cellulose can be improved via pre-chemical modification. For example, alkaline-soluble cellulose carbamate can be produced via a reaction between cellulose and urea at elevated temperatures (generally around the melting point of urea). ${ }^{[17]}$ Cellulose carbamate has good solubility in $\mathrm{NaOH}$ solution, especially in the presence of $\mathrm{ZnO}$, and it has been used to produce cellulose-based membranes ${ }^{[18]}$ and filaments ${ }^{[19]}$.

Urea and many of its derivatives are promising chemicals for cellulose modification because they can be produced in a sustainable way from carbon dioxide ${ }^{[20,21]}$, thus providing a method via which to attach carbon dioxide to biomaterials with improved properties. In this study, the synthesis of novel cellulose methyl carbamate $(\mathrm{CMeC})$ was studied using a reactive deep eutectic solvent (DES) based on dimethylurea and $\mathrm{ZnCl}_{2}$. DESs show promising properties, such as good solvent capacity, and in chemical reactions, they can function as both catalysts and reagents. ${ }^{[22]}$ Despite their good properties (e.g., low toxicity, minimal vapor pressure and good biodegradability), some DESs have proven to be unstable under certain conditions. ${ }^{[23]}$ This, however, can be used as an advantage for novel chemical modifications. ${ }^{[24]}$

Here, the synthesis of CMeCs was studied as a solvent-free reaction by allowing cellulose to react with an excess of DESs at an elevated temperature. The products were characterized by elemental analysis, attenuated total reflection infrared spectroscopy (ATR-IR), X-ray photoelectron spectroscopy (XPS), and ${ }^{1} \mathrm{H}$ NMR. Solubility in $\mathrm{NaOH}$ solution was studied after a freeze-thawing process.

\section{Results and Discussion}

$\mathrm{CMeC}$ were synthesized using reactive DES based on dimethylurea and $\mathrm{ZnCl}_{2}$. At a molar ratio of 10:3, dimethylurea and $\mathrm{ZnCl}_{2}$ formed a clear, low-viscosity solution at $100^{\circ} \mathrm{C}$ (Figure 1). $\mathrm{CMeC}$ synthesis was carried out under solvent-free conditions using a 10-fold molar excess of dimethylurea as compared to cellulose (amount of $\mathrm{ZnCl}_{2}$ was thus $30 \mathrm{~mol}-\%$ of dimethylurea). It should be noted that a $0.5 \mathrm{M}$ solution of $\mathrm{HCl}$ was utilized during the washing of products because white precipitation appeared after the addition of deionized water to the DES (Figure 1). The precipitation of zinc upon the addition of water has been previously observed when DES based on urea and $\mathrm{ZnCl}_{2}$ was used in the dissolution of lignin. ${ }^{25]}$ 


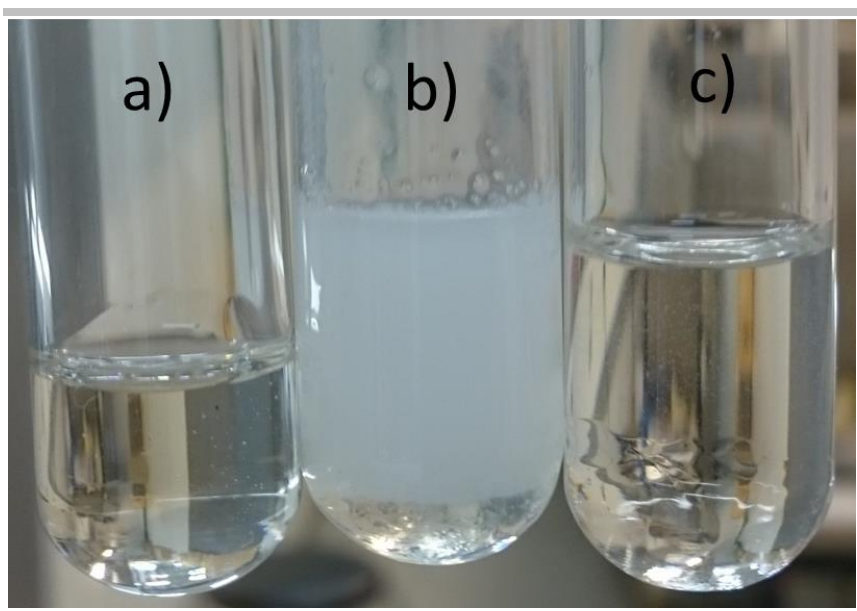

Figure 1. Dimethylurea-ZnCl2 (molar ratio of 10:3) DES after a) preparation at $100^{\circ} \mathrm{C}, \mathrm{b}$ ) addition of water, and c) addition of $0.5 \mathrm{M} \mathrm{HCl}$

The nitrogen content of $\mathrm{CMeCs}$ increased when a longer reaction time was used and at a maximum nitrogen content of $1.37 \%$, corresponding to a DS of 0.17 , which was obtained using $3 \mathrm{~h}$ reaction time (Table 1). It was also observed that the presence of $\mathrm{ZnCl}_{2}$ has an important effect on the reaction because a nitrogen content of $0.26 \%$ (DS of 0.03 ) was obtained using only dimethylurea (Sample 5). In addition, Sample 3, which was produced by drying cellulose and DES suspension in an oven, already had a higher DS (0.04) as compared to Sample 5, further demonstrating the important effect of the $\mathrm{ZnCl}_{2}$ on cellulose carbamation.

Table 1. Reaction conditions used to produce CMeCs, degree of polymerization product, original cellulose, and degree of substitution of products ( $-=$ not used, $+=$ used, and ${ }^{*}=$ not measured)

\begin{tabular}{|c|c|c|c|c|c|}
\hline \multirow{2}{*}{ Sample } & \multicolumn{2}{|c|}{ Chemicals } & \multirow{2}{*}{$\begin{array}{c}\text { Reactio } \\
\mathrm{n} \text { time at } \\
150^{\circ} \mathrm{C}\end{array}$} & \multirow{2}{*}{$\begin{array}{c}\text { Degree of } \\
\text { polymerization }\end{array}$} & \multirow{2}{*}{$\begin{array}{l}\text { Degree of } \\
\text { substitution }\end{array}$} \\
\hline & $\mathrm{DMU}$ & $\mathrm{ZnCl}_{2}$ & & & \\
\hline $1^{\mathrm{a}}$ & - & - & - & 1820 & * \\
\hline 2 & + & + & - & 847 & $0.04 \pm 0$ \\
\hline 3 & - & - & 1 & 1660 & * \\
\hline $4^{b}$ & - & + & 1 & & \\
\hline 5 & + & - & 1 & 905 & $\begin{array}{l}0.03 \pm \\
0.003\end{array}$ \\
\hline 6 & + & + & 1 & 1220 & $0.14 \pm 0$ \\
\hline 7 & + & + & 1.5 & 686 & $0.16 \pm 0$ \\
\hline 8 & + & + & 3 & 847 & $\begin{array}{l}0.17 \pm \\
0.003\end{array}$ \\
\hline
\end{tabular}

aOriginal cellulose sample; ${ }^{b}$ completely charred product, therefore properties were not measured; ${ }^{\circ}$ calculated from elemental analysis results

The chemical modification of cellulose can have a severe effect on the DP of cellulose, especially at a high temperature and in the presence of acids (here, Lewis acid $\mathrm{ZnCl}_{2}$ ). When the reaction was performed using only $\mathrm{ZnCl}_{2}$ (a three-fold molar excess of $\mathrm{ZnCl}_{2}$ as compared to cellulose, Sample 3), a completely charred product was obtained, indicating that the formation of DES between dimethylurea and $\mathrm{ZnCl}_{2}$ protects cellulose against $\mathrm{ZnCl}_{2}$ - catalyzed dehydration. From Table 1, it can be seen that the DP of the original cellulose pulp decreases from 1820 to $1200-686$ during the reactions (it should be noted that due to the slightly different chemical nature and possible dissolution of hemicelluloses, the DPs of the various samples are directional). Most of the degradation of cellulose takes place during the sample drying at $100{ }^{\circ} \mathrm{C}$, because Sample 3 (only dried at $100{ }^{\circ} \mathrm{C}$, together with DES components) has a similar DP as Samples 6 and 7 . Interestingly, the sample produced using only dimethylurea (Sample 5) has a similar DP to the sample produced using DES. This further indicates that when used as a part of DES, $\mathrm{ZnCl}_{2}$ has low dehydration effect on cellulose fibers.

The chemical alteration of cellulose's structure during $\mathrm{CMeC}$ synthesis was studied using an ATR-IR (Figure 2). In addition to the typical cellulose vibration bands, a new band at $1703 \mathrm{~cm}^{-1}$, corresponding to the carbonyl stretching of the carbamate group, was observed for all CMeCs. The $\mathrm{NH}$ deformation band of the secondary amide and methyl stretching were also observed at 1536 and $1260 \mathrm{~cm}^{-1}$, respectively. A similar spectrum was also obtained from Sample 8 after dissolution in $9 \% \mathrm{NaOH}$ and regeneration via ethanol. These results indicate that methyl carbamate functional groups were efficiently introduced to cellulose and no significant chemical alteration took place via alkaline dissolution and regeneration.

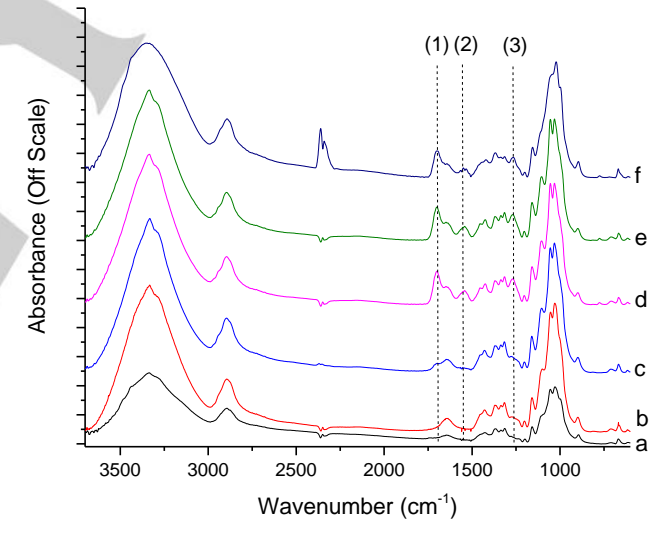

Figure 2. ATR-IR spectra of original cellulose (a), cellulose dried in an oven without chemicals (b), $\mathrm{CMeC}$ produced without $\mathrm{ZnCl} 2$ (c) and with DES using a reaction time of 1 (d) and 3 hours (e), and the dissolved and regenerated sample 3 (f). The most distinct $\mathrm{CMeC}$ bands are numbered and presented as dashed lines: (1) $\mathrm{C}=\mathrm{O}$ of carbonyl group, (2) $\mathrm{N}-\mathrm{H}$ of secondary amide group, and (3) C$\mathrm{H}$ of methyl group.

Further chemical analysis was performed using ${ }^{1} \mathrm{H}$ NMR (Figure 3). A spectrum was measured from Sample 7 (DS of 0.16 ) in $3 \%$ $\mathrm{NaOD} / \mathrm{D}_{2} \mathrm{O}$ solution. Due to the insolubility of the original cellulose, a reference spectrum could not be obtained. However, in the ${ }^{1} \mathrm{H}$ NMR spectrum of low-molecular-weight cellulose (DP = 15) in $4 \%$ $\mathrm{NaOD} / \mathrm{D}_{2} \mathrm{O}$, all the proton resonances of the anhydroglucose unit appear in the 4.5-3.0 ppm region. ${ }^{[26]}$ These peaks were also observed in the spectrum of $\mathrm{CMeC}$. In addition, a new broadened peak appears at $2.53 \mathrm{ppm}$, which can be assigned to the methyl group of the methyl carbamate moiety. The small signal at 2.48 ppm is most likely due to the presence of a small amount of 
unreacted dimethylurea (the spectrum of dimethylurea in 3\% $\mathrm{NaOD} / \mathrm{D}_{2} \mathrm{O}$ can be seen in Supporting Information, Figure S2). The sharp peaks at 2.41 and 2.09 ppm are most likely due to the presence of unknown side-products, possibly formed during the chemical modification of cellulose or by the hydrolysis of the methylcarbamate group of $\mathrm{CMeC}$. Based on the ratio of the signal integral of the methyl group to the sum of the proton signal integrals of the cellulose backbone, which should be 9:7 if the DS is 3.00 , the DS of $\mathrm{CMeC}$ is 0.15 , which is consistent with the DS value obtained via elemental analysis.

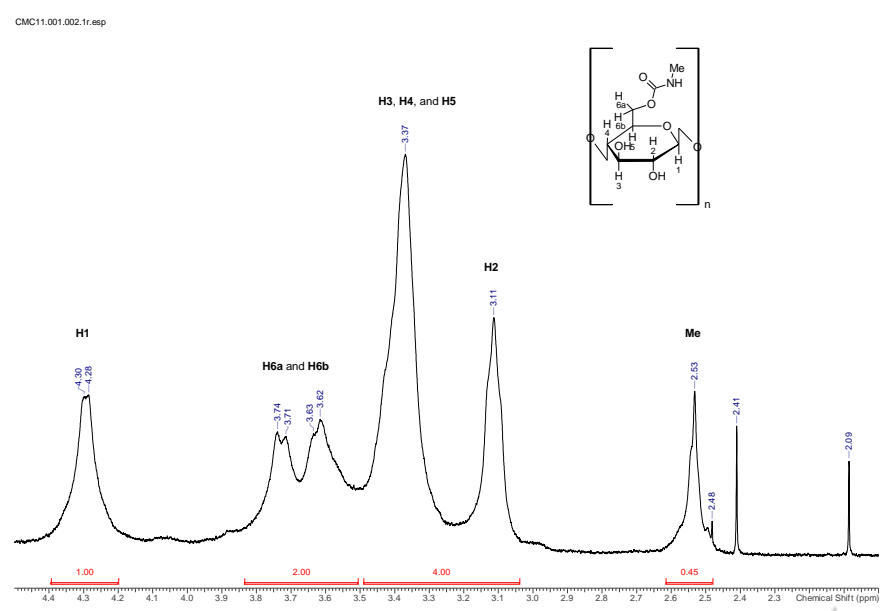

Figure 3. $1 \mathrm{H}$ NMR spectrum of $1 \% \mathrm{CMeC}$ (Sample 7) in 3\% NaOD/D2O

XPS measurement was performed to investigate the presence of zinc on cellulose fibers. Weight-\% of carbon, oxygen, nitrogen and zinc in original cellulose, Sample 4 (produced without $\mathrm{ZnCl}_{2}$ ), and Sample 8 (produced using DES) are presented in Table 2. Some nitrogen and zinc detected in original cellulose samples might originate from remaining impurities and the amount of zinc actually decreased after chemical modification. This indicates that no zinc derived from DES during the cellulose carbamation remains in fiber. It should be noted that XPS is only surface analysis, however, due to the heterogeneous nature of cellulose carbamation, it is unlikely that significant amount of zinc remains inside of fibers. From the Table 2, it can be also seen that the ratio between nitrogen and carbon increases during the cellulose carbamation and the results are well in line with the elemental analysis (data not shown).

Table 2. Weight-\%, and ratios between nitrogen/carbon and zinc/carbon of original cellulose, Sample 4 and Sample 8 determined by XPS.

\begin{tabular}{|c|c|c|c|c|c|c|}
\hline \multirow[b]{2}{*}{ Sample } & \multirow[b]{2}{*}{ C } & \multicolumn{2}{|c|}{ Atom weight-\% } & \multirow[b]{2}{*}{$\mathrm{Zn}$} & \multirow{2}{*}{$\mathrm{N} / \mathrm{C}$} & \multirow{2}{*}{$\mathrm{Zn} / \mathrm{C}$} \\
\hline & & 0 & $\mathrm{~N}$ & & & \\
\hline $\begin{array}{l}\text { Original } \\
\text { cellulose }\end{array}$ & 52.75 & 46.77 & 0.3 & 0.19 & 0.0057 & 0.0036 \\
\hline Sample 4 & 56.71 & 42.91 & 0.35 & 0.03 & 0.0062 & 0.0005 \\
\hline Sample 8 & 55.42 & 42.41 & 2.15 & 0.02 & 0.0388 & 0.0004 \\
\hline
\end{tabular}

The chemical modification of cellulose is assumed to proceed through a similar mechanism to that proposed for cellulose carbamate synthesis with urea. ${ }^{[16]}$ Dimethylurea first degrades, forming methylamine and methylisocyanate, which then react with the hydroxyl groups of cellulose (Scheme 1). Based on the results obtained for the chemical characterization of $\mathrm{CMeCs}$, it appears that the reaction is induced by heat and significantly catalyzed by the presence of $\mathrm{ZnCl}_{2} . \mathrm{ZnCl}_{2}$ may also increase the reactivity of cellulose towards isocyanate.

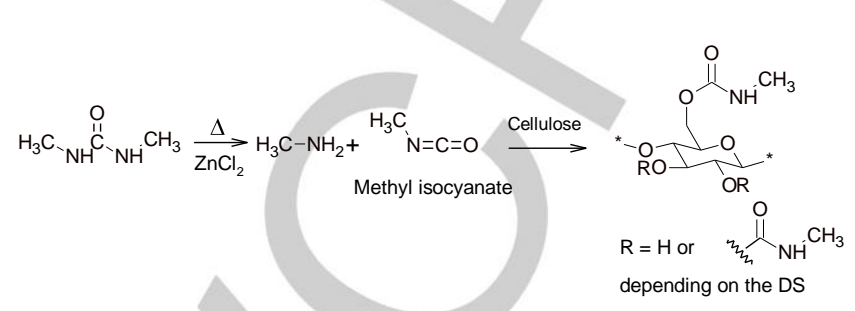

Scheme 1. Schematic illustration of possible reaction mechanism of the synthesis of $\mathrm{CMeC}$ using dimethylurea and $\mathrm{ZnCl} 2 \mathrm{DES}$ via dimethylurea degradation

The effect of the chemical modification on the solubility of dissolving pulp was investigated by preparing a $1 \%$ cellulose dispersion in $9 \% \mathrm{NaOH}$ solution. After freezing and thawing, both the original dissolving pulp and dissolving pulp treated in a similar way as in $\mathrm{CMeC}$ synthesis but without chemicals formed turbid solutions in which intact cellulose fibers were clearly visible (Figure 4). Sample 5, which was obtained without $\mathrm{ZnCl}_{2}$ formed more clear solution. However, some intact fibers still remained, indicating only partial solubility. A similar solution, only slightly less hazy, was obtained from $\mathrm{CMeC}$ with a DS of 0.14 (Sample $6)$.

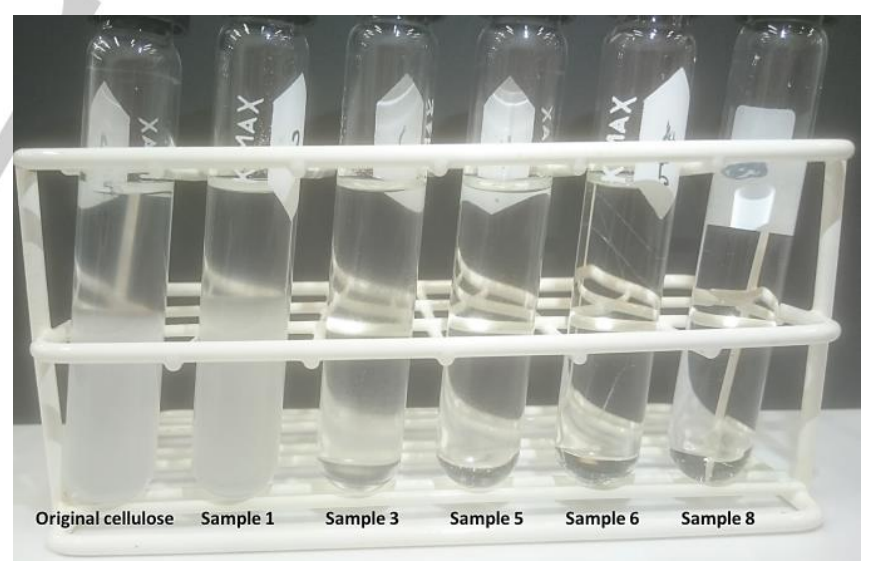

Figure 4. Images demonstrating the solubility of various samples (1\%) in $9 \%$ $\mathrm{NaOH}$ solution. From left to right: original cellulose fibers (Sample 1), fibers heated without chemicals (Sample 3), $\mathrm{CMeC}$ obtained without $\mathrm{ZnCl} 2$ (Sample 5), and $\mathrm{CMeCs}$ obtained using DES after 1- (Sample 6), 1.5- (Sample 7), and 3- (Sample 8) hour reactions.

On the other hand, both Samples 7 and 8 (DSs of 0.16 and 0.17 , respectively) formed clear, slightly viscous solutions in $9 \% \mathrm{NaOH}$. The solubility of these two samples was further investigated using more dilute $\mathrm{NaOH}$ solutions. Clear solutions were obtained from Sample 8 in $8-4 \% \mathrm{NaOH}$ solution, but in $3 \% \mathrm{NaOH}$, a slightly 
turbid solution was formed. Sample 7, on the other hand, was soluble even in $3 \% \mathrm{NaOH}$. However, more dilute $\mathrm{NaOH}$ solutions resulted in the formation of turbid solutions, in which intact fibers were clearly visible. Based on the solubility studies, a minimum DS of 0.16 is required for efficient solubility. However, when the DS is increased, the solubility begins to decrease, possibly due to the hydrophobicity of the methyl group (e.g., the improvement of the solubility of cellulose in organic solvent after the introduction of a methyl carbonate group ${ }^{[27]}$ ).

The dissolution of cellulose is highly affected by the DP of the sample, and as observed above, all the CMeCs had significantly lower DPs as compared to the original cellulose pulp. Therefore, the hydrolysis of cellulose during chemical modification can be seen as one of the driving forces toward alkaline solubility. However, the DPs of the CMeCs were still relatively high as compared to that of the cellulose dissolved in $\mathrm{NaOH}$ solution without additives. ${ }^{[15]}$ The addition of external solubilization agents, such as urea, can improve the solubility of cellulose. However, the dissolution of high-DP cellulose is still limited. ${ }^{[28]}$ Therefore, the $\mathrm{DS}$ of $\mathrm{CMeC}$ also has an important effect on the solubility. The products prepared only by drying at $100{ }^{\circ} \mathrm{C}$, without curing (Sample 3, DS of 0.04); the sample produced using only dimethylurea (Sample 5, DS of 0.02), and the sample produced by curing for one hour (Sample 6, DS of 0.14 ) were insoluble in $9 \% \mathrm{NaOH}$. Only samples with DSs of 0.16 or higher showed good alkaline solubility. There was also no significant difference between the DPs of the CMeCs. These results indicate that the efficient substitution of the hydroxyl groups of cellulose with methyl carbamate decreases the hydrogen bonding of cellulose to permit dissolution in an aqueous solvent. Further studies should be conducted to optimize the DS towards dissolution, especially with higher cellulose concentrations.

\section{Conclusion}

It was found that the reactivity of DES based on dimethylurea and $\mathrm{ZnCl}_{2}$ could be taken as an advance in the synthesis of a novel cellulose carbamate. The chemical group content of $\mathrm{CMeC}$ can be adjusted by increasing the reaction time, and a product with a DS higher than 0.16 should be very readily soluble to $\mathrm{NaOH}$ solution, even at a low $\mathrm{NaOH}$ concentration (3\%) without any additives, whereas the original cellulose pulp was practically insoluble. Even though cellulose was observed to hydrolyze during the reaction, the main driving force towards alkaline solubility was found to be the amount of methyl carbamate groups. The only other component beyond the DES and cellulose wood pulp was water, making this synthesis a potentially sustainable way to obtain soluble cellulose from wood fibers. This study also demonstrate that there is possibility to produce alkyl carbamates even without using toxic isocyanates (isocyanates are generated in situ from much less toxic chemical (dimethylurea)). Furthermore, dimethylurea can be produced from carbon dioxide, making this method an efficient way to transfer waste carbon dioxide to a bio-based material with improved properties. However, future studies should be conducted to investigate the possibility to recycle DES and replace $\mathrm{ZnCl} 2$ with less hazardous chemical for further improve the environmental feasibility of the synthesis of $\mathrm{CMeC}$.

\section{Experimental Section}

\section{Materials}

Dissolving cellulose pulp (softwood) was obtained in the form of dry sheets and used as a cellulose material after disintegration in deionized water. The properties of cellulose pulp are discussed elsewhere. ${ }^{[29]}$ Dimethylurea and $\mathrm{ZnCl}_{2}$ were obtained from Sigma Aldrich (Germany). $\mathrm{HCl}$ solution ( 0.5 M) was purchased from VWR (Finland)

\section{Synthesis of cellulose methyl carbamate}

First, $133.3 \mathrm{~g}$ of $1.5 \%$ cellulose suspension in water (dry matter content of $2 \mathrm{~g}, 12.34 \mathrm{mmol})$ was mixed with $10.9 \mathrm{~g}(123.4 \mathrm{mmol})$ of dimethylurea and

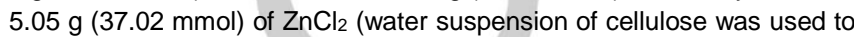
ensure the efficient mixing and reaction between cellulose fibers and DES). The molar ratio between dimethylurea and $\mathrm{ZnCl} 2$ was 10:3. The reaction mixture was first dried in an oven at $100^{\circ} \mathrm{C}$ for $24 \mathrm{~h}$. After drying, the sample was transferred to an oven at $150{ }^{\circ} \mathrm{C}$ for a pre-determined length of time (Table 1). After the desired time had elapsed, the sample was removed from the oven and allowed to cool for $5 \mathrm{~min}$ at room temperature. Then, $100 \mathrm{ml}$ of $0.5 \mathrm{M} \mathrm{HCl}$ solution was added, and the suspension was thoroughly mixed, filtrated, and washed with $50 \mathrm{ml}$ of $0.5 \mathrm{M} \mathrm{HCl}$ solution, followed by washing with $500 \mathrm{ml}$ of deionized water. The product was collected and dried in an oven at $60^{\circ} \mathrm{C}$ for $24 \mathrm{~h}$.

Reference samples were produced in a similar way, but ether dimethylurea, $\mathrm{ZnCl}_{2}$, or both were excluded. One sample was also produced via only drying at $100{ }^{\circ} \mathrm{C}$ for $24 \mathrm{~h}$ with dimethylurea and $\mathrm{ZnCl}_{2}$, without curing at $150^{\circ} \mathrm{C}$.

The elemental analysis of the samples was performed using a PerkinElmer CHNS/O 2400 Series II elemental analyzer (USA), and the degree of substitution (DS) was calculated via Equation 1[30]:

$$
D S=\frac{N \times 162.15}{1401-(N * 57.56)}
$$

where $\mathrm{N}$ is nitrogen content, 162.15 the molecular weight of the anhydroglucose unit of cellulose, and 57.56 was the molecular weight of the methylcarbamate group.

\section{Attenuated total reflection infrared spectroscopy}

The chemical characterization of raw cellulose and chemically modified cellulose was performed using an ATR-IR. The spectra were collected from dried samples with a Bruker Tensor II FT-IR Spectrometer with a Hyperion 3000 FT-IR Microscope (USA). Spectra were obtained in the $600-4000 \mathrm{~cm}^{-1}$ range, and 40 scans were taken at a resolution of $4 \mathrm{~cm}^{-1}$ for each sample.

\section{Dissolution experiments}

For dissolution experiments, $0.1 \mathrm{~g}$ of sample was first dispersed in $10 \mathrm{ml}$ of $0-9 \% \mathrm{NaOH}$ solution at room temperature. The dispersion was then placed in a fridge at $-24{ }^{\circ} \mathrm{C}$ for $24 \mathrm{~h}$. The dispersion was then transferred to room temperature and vigorously stirred until room temperature was reached. Dissolution was observed visually and via an optical microscopy.

\section{${ }^{1}$ H NMR}

The sample was dissolved similar way as described for the dissolution experiments, except that a $1 \%$ sample solution was produced using $3 \%$ 
$\mathrm{NaOD}$ in $\mathrm{D}_{2} \mathrm{O}$ solution. The sample was placed in a $5 \mathrm{~mm}$ NMR tube. The ${ }^{1} \mathrm{H}$ NMR spectrum was recorded by using a Bruker Ascend $400 \mathrm{MHz}$ spectrometer at ambient temperature.

\section{Degree of polymerization}

The average degree of polymerization (DP) of the original cellulose pulp, DES-treated cellulose, and nanofibrillated celluloses was evaluated using the limiting viscosity, as measured in CED solution according to the ISO 5351 standard. The samples were freeze-dried prior to measurement. The limiting viscosity values were converted to DP using Eq. (2),

$$
D P=\left(\frac{(1.65[\eta]-116 H}{C}\right)^{1.111}
$$

where $[\eta]$ is the limiting viscosity, $C$ is the mass fraction of the cellulose and $H$ is the mass fraction of the hemicelluloses. This calculation corrects for the contribution of the hemicelluloses to the limiting viscosity number and DP of the cellulose, assuming that the average DP of the hemicelluloses is 140 .

\section{X-ray photoelectron spectroscopy}

XPS of original cellulose and cellulose carbamate obtained with and without $\mathrm{ZnCl}_{2}$ was obtained using Thermo Fisher Scientific ESCALAB 250Xi (UK) XPS equipped with a monochromatic AIKa X-ray source and operated at $300 \mathrm{~W}$ with a combination of electron flood gun and ion bombarding for charge compensation. The take-off angle was $45^{\circ}$ in relation to the sample surface. The low-resolution survey scans were taken with a $1 \mathrm{eV}$ step and $150 \mathrm{eV}$ analyzer pass energy; high-resolution spectra were taken with a $0.1 \mathrm{eV}$ step and $20 \mathrm{eV}$ analyzer pass energy. All measurements were made in an ultra-high vacuum chamber pressure $\left(5 \times 10^{-9} \mathrm{mbar}\right)$. Prior the measurement, dry sample was pressed on the indium film.

\section{Acknowledgements}

J.A.S. would like to thank the Kone Foundation for its financial support. Ms. Elisa Wirkkala is gratefully acknowledged for help with the elemental and limiting viscosity analysis. Mr. Santtu Heinilehto is gratefully acknowledged for XPS measurement and Dr. Ossi Laitinen for help with analysis of XPS results. The facilities of the Center of Microscopy and Nanotechnology of the University of Oulu were utilized in this research.

Keywords: Cellulose $\cdot$ deep eutectic solvent $\bullet$ green chemistry $\bullet$ biomass •

[1] T. Huber, J. Müssig, O. Curnow, S. Pang, S. Bickerton, M. P. Staiger, J. Mater. Sci. 2011, 47, 1171.

[2] S. Zhu, Y. Wu, Q. Chen, Z. Yu, C. Wang, S. Jin, Y. Ding, G. Wu Green Chem. 2006, 8, 325.

[3] T. R. Dawsey, C. L. McCormick, J. Macromol. Sci. Part C 1990, 30, 405.

[4] T. Rosenau, A. Potthast, I. Adorjan, A. Hofinger, H. Sixta, H. Firgo, P. Kosma, Cellulose n.d., 9, 283.

[5] S. Fischer, H. Leipner, K. Thümmler, E. Brendler, J. Peters, Cellulose n.d., 10, 227

[6] A. Pinkert, K. N. Marsh, S. Pang, M. P. Staiger, Chem. Rev. 2009 109, 6712

[7] C. Olsson, G. Westm, in Cellul. - Fundam. Asp. (Ed: T.G.M. Van De Ven), InTech, 2013.

[8] R. Rinaldi, Chem. Commun. 2010, 47, 511.

[9] M. Abe, K. Kuroda, H. Ohno, ACS Sustain. Chem. Eng. 2015, 3, 1771.
[10] J. Cai, L. Zhang, Macromol. Biosci. 2005, 5, 539.

[11] L. Zhang, D. Ruan, S. Gao, J. Polym. Sci. Part B Polym. Phys. 2002, 40, 1521.

[12] S. Grönqvist, T. Kamppuri, T. Maloney, M. Vehviläinen, T. Liitiä, A. Suurnäkki, Cellulose 2015, 22, 3981.

[13] B. Duchemin, D. L. Corre, N. Leray, A. Dufresne, M. P. Staiger, Cellulose 2015, 23, 593.

[14] S. Schmidt, T. Liebert, T. Heinze, Green Chem. 2014, 16, 1941

[15] N. L. Moigne, P. Navard, Cellulose 2009, 17, 31.

[16] S. Johan-Fredrik, H. Jouko, T. Olli, F. Jan, E. Vidar, E. Kurt Procedure for Manufacturing Cellulose Carbamate Fibres of Films, 1985, ZA8408118 (B).

[17] H.-P. Fink, J. Ganster, A. Lehmann, Cellulose 2013, 21, 31

[18] F. Fu, Y. Guo, Y. Wang, Q. Tan, J. Zhou, L. Zhang, Cellulose 2014 21, 2819.

[19] F. Fu, Q. Yang, J. Zhou, H. Hu, B. Jia, L. Zhang, ACS Sustain. Chem. Eng. 2014, 2, 2604

[20] X. Xiang, L. Guo, X. Wu, X. Ma, Y. Xia, Environ. Chem. Lett. 2012, 10 295.

[21] R. V. Chaudhari, S. P. Gupte, A. A. Kelkar, D. S. Kolhe, Process for the Preparation of Alkyl Carbamates., 1991, EP0442173 (A1).

[22] E. L. Smith, A. P. Abbott, K. S. Ryder, Chem. Rev. 2014, 114, 11060.

[23] S. P. Simeonov, C. A. M. Afonso, RSC Adv. 2016, 6, 5485

[24] E. R. Parnham, E. A. Drylie, P. S. Wheatley, A. M. Z. Slawin, R. E. Morris, Angew. Chem. Int. Ed. 2006, 45, 4962.

[25] H. Lian, S. Hong, A. Carranza, J. D. Mota-Morales, J. A. Pojman, RSC Adv. 2015, 5, 28778

[26] A. Isogai, Cellulose n.d, 4,99

[27] S. R. Labafzadeh, K. J. Helminen, I. Kilpeläinen, A. W. T. King, ChemSusChem 2015, 8, 77.

[28] Z. Shi, Q. Yang, S. Kuga, Y. Matsumoto, J. Agric. Food Chem. 2015, $63,6113$.

[29] J. Sirvio, U. Hyvakko, H. Liimatainen, J. Niinimaki, O. Hormi, Carbohydr. Polym. 2011, 83, 1293.

[30] J. Liesiene, J. Kazlauske, Cellul. Chem. Technol. 2013, 47, 515 


\section{Entry for the Table of Contents}

\section{FULL PAPER}

The reactive deep eutectic solvent based on dimethylurea and zinc chloride was used to obtain cellulose methylcarbamate. Compared to original wood cellulose fibers, cellulose methylcarbamate exhibited good alkaline solubility even at low $\mathrm{NaOH}$ concentration.

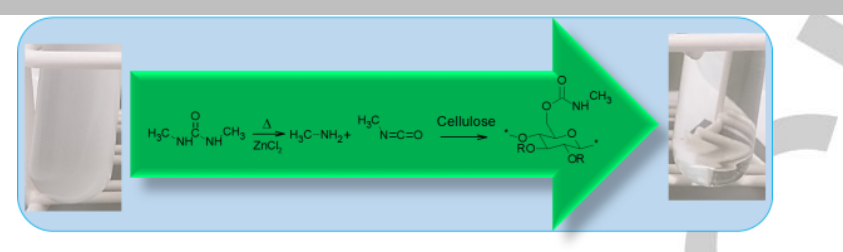

Juho Antti Sirviöa*, Juha P. Heiskanen ${ }^{b}$

Page No. - Page No.

Synthesis of alkaline-soluble cellulose methyl carbamate using reactive deep eutectic solvent 